\title{
Use of time-lapse resistivity tomography to determine freshwater lens morphology
}

\author{
Mohamad Faizal Tajul Baharuddin , Zubaidah Ismail , Siti Zulaikha Othman , \\ Samsudin Taib , Roslan Hashim
}

Freshwater-lens is a primary source of water for water

supply for domestic and agricultural purposes [1] in remote

areas such as islands. Density differences between

freshwater and saltwater create a lens-shaped body of

freshwater overlying saltwater [2]. Groundwater recharge

in such areas depends on the amount of precipitation. Seawater

entry and other forms of contamination like effluents

which may require special attention [3] in the

planning and management of fresh groundwater [4-6].

Understanding fresh water lens characteristics at limited

recharge areas is important to ensure sustainability of

groundwater [7]. Among the common factors discussed on freshwater lens are seasonal, tide effects and hydrogeology

conditions.

Different qualitative and quantitative methods were

adopted for investigating the morphology and freshwater

lens flows in islands. Vacher [8] demonstrated the

analytical mathematical solution approach assisted with

monitoring well data to investigate the morphology characteristics

of freshwater lens across the Bermuda Island

with variation of permeability which influenced the fresh

groundwater occurrence and behavior. Ayers and Vacher

[9] used a technique incorporating surface geology, water

levels and their variations, surface geophysics and subsurface

core samples to determine the freshwater-lens

morphology at Micronesian atoll islands in the Pacific

Ocean. Results indicated that the reef-flat plate acts as

confining bed along the ocean side of freshwater lens.

Studies on the lens morphology on small islands by

Comte et al. [13] give useful information on both the recharge and water uptake due to evapotranspiration by vegetation. Electrical resistivity tomography was applied,

giving relevant information on the lens structure. Variable

density groundwater flow models were applied to simulate

freshwater behavior. Cross validation of the geoelectrical

model and the groundwater model showed that recharge 
exceeds water uptake in dunes with little vegetation, allowing the lens to develop.

Studies of freshwater lens flow movements which facilitated spatial and time domain constraint using numerical flow modeling were conducted by the following researchers. Oberdorfer [14] used two dimensional SUTRA models which incorporates density-dependent flow for case study at atoll islands of the Pacific Ocean. Results showed that the tidal variations were predominant driving forces for flow beneath the island. Vertical propagation of tidal signals tended to be dominant in the middle of the island whereby both horizontal and vertical propagation were significant near the seawater margins. Schneider and Kruse [11] extended their studies at barrier islands in Florida, by using SEAWAT numerical modeling code coupled with MODFLOW and MT3DMS to simulate three-dimensional variable-density groundwater flow. Variable density groundwater flow models confirmed that spatial variability of recharge values could account for the observed lens asymmetry on these islands. The coastal erosion rates were sufficiently rapid that the freshwater lens might not be in equilibrium with the current boundary conditions.

Other researchers have also conducted studies on the lens of freshwater beneath tropical islands where the supply of water is vital [15-18]. There appeared to be upper and lower bounds on the flow rates that produce steady interface shapes. The height of the seepage faces was dominated by the density ratios.

A recent study was conducted using a simple steadystate approximation to provide insight into the key climatic, hydro-geological, physiographic, and management factors that influence the quantity and salinity of freshwater lenses in small Pacific Islands [7]. The lens morphology can be changed by tide effects [14]. Strategies to conserve and manage fragile small island groundwater systems were proposed to ensure their sustainability.

Geological formation, recharge, tides and human factors are common factors influencing the morphology in many cases studied. The geologic formation consists of heterogeneous material creating a variety of porous material resulting in different values of hydraulic conductivity [2,19]. High hydraulic conductivity materials are easily penetrated into than low hydraulic conductivity materials $[7,14]$

An overview of different approaches from previous studies was given by Izuka and Gingerich [10] for studying 
the thickness of freshwater lens in volcanic shield in

Hawaii. Results show that the groundwater system in the southern Lihue Basin is characterized by flow through low-permeability rocks, which produces a thick freshwater lens, steep head gradients, and a water table that rises from near sea level at the coast to hundreds of meters above sea level from a few kilometers inland. The findings are different from the conventional conceptual model for groundwater occurrence on other area of shield-volcano islands of relatively high permeability.

Rotzoll and el-Kadi [12] measured groundwater levels that were used to approximate the midpoint of the transition zone by using the Ghyben-Herzberg principle to investigate changes of freshwater lens thickness at basaltic islands in Hawaii. Geologic factor controlled the morphology of freshwater lens where the thickest measured freshwater lens was $262 \mathrm{~m}$ in dike-free, volcanic rock aquifers overlain by thick coastal sediments. The thinning of the freshwater lenses was the result of long-term groundwater withdrawal and reduced recharge over many years.

The electrical resistivity tomography (ERT) method has been applied by Ranieri et al. [20] in an archaeological survey over two different weather conditions. The results show that time-lapse prospecting can increase the resistivity contrast between archaeological structures and soil. The applicability of the Electrical Resistivity technique for saline interface tracing has also been conducted [21]. The method of two-dimensional time-lapse electrical resistivity tomography (2D time-lapse ERT) were applied for monitoring the structural stability of the roof of the Great Hall cavern in the Harrison's cave system, Barbados [22]. The potential and feasibility of groundwater exploration next to the Thomazo River in the Fond D'Or watershed in Saint Lucia was determined.

This current study focuses on geological formation, tide effects and seasonal factor influencing the freshwater lens morphology. TLRET assisted with borehole data, geology formation history and hydraulic conductivity data were used to make a qualitative assessment of freshwater lens morphology. The study can enhance the understanding of freshwater lens characteristics and improve the groundwater withdrawal strategy via TLERT technique [23].

Study area

Carey Island is on the west coast of the Selangor state in Peninsular Malaysia. It is separated from the Selangor coast by the Klang River on its north and the Langat River on its east. The study area faces the sea as shown in Figs. 1 and 2. 
An earlier study on groundwater resources of the area was

conducted in 2002 [24]. From the analysis of local precipitation

on Carey Island, two seasons can be deduced based on data from 2000 to 2010 [23]. The wet season occurs in the months of August-December with a mean rainfall of $280 \mathrm{~mm}$. The lowest rainfall representing the dry season occurs in the months of February-March with a mean of $150 \mathrm{~mm}$.

Selangor was predicted to be 1 million $\mathrm{m}_{3}$ short of water daily [25]. Water shortage is regular on Carey Island, so people harvest rain. The Department of Mineral and Geo-Science have been requested to determine the island's water-supply potential. The hydrogeology of the area has been studied to assist strategies of groundwater exploration $[25,26]$. Efforts have not been successful due to brackish and saline water which intercalated in the aquifers [23].

Full text available at :

http://ac.els-cdn.com/S0263224112004022/1-s2.0-S0263224112004022-main.pdf? tid=0193a068-66e4-11e39d5c-00000aacb35d\&acdnat $=1387261701$ f1ef013b9e4cd175ce56083846401d67

http://www.sciencedirect.com/science/article/pii/S0263224112004022 